Jpn. J. Med. Mycol.

Vol. 32, Suppl. 63-73, 1991

ISSN $0916-4804$

\title{
The Structure and Function of Candida albicans Cell Wall
}

\author{
Maxwell G. SHEPHERD \\ Experimental Oral biology Unit, Faculty of Dentistry, \\ University of Otago, Dunedin, New Zealand
}

\begin{abstract}
The wall and outer surface of pathogenic fungi is involved in adhesion and cell shape maintenance, and acts as a barrier to metabolites and drugs. In addition the cell wall contains immunogenic determinants, immunomodulators and secreted enzymes. The cell wall of C.albicans comprises some $30 \%$ of the dry weight of the cell and is composed predominantly of mannoproteins and $\beta$-glucans with small quantities of chitin, protein and lipid. Transmission electronmicroscopy of the wall reveals a number of different layers; the thickness and number of these layers varies during germ-tube formation and the cell cycle. The outer fuzzy layer of the wall contains receptors that bind plastic, laminin, fibrinogen, and $\mathrm{C} 3$ fragments of complement. The $\beta 1,3$ and $\beta 1,6$ glucans and chitin are the polymers which endow rigidity on the cell wall. These polymers form a microfibrillar scaffolding upon which other macromolecules, particularly mannoproteins are bound.

The wall mannoproteins are highly branched polysaccharides primarily composed of mannose units attached to protein through a G1cNac dimer bridge and asparagine. There are also smaller numbers of 0 -linked mannoproteins where the mannose units are attached to protein through serine and threonine residues. The mannoproteins have a backbone of $\alpha-1,6$ linked mannose units to which side chains of mannoses attach via $\alpha-1,2$ - and occasionally $\alpha-1,3$ bonds. The side chains are the major antigenic determinants and the $\mathrm{A}$ and $\mathrm{B}$ serotypes are distinguished by differences between these side chains. A model for cell wall growth and development will is described.
\end{abstract}

\section{Introduction}

Cell wall studies of pathogenic fungi are important for a variety of reasons. Firstly, Candida albicans is a dimorphic organism and in infected tissues a mixture of yeast cells and hyphal elements is found. Since it is the rigid structure of the wall that confers mechanical stability on the cell maintaining its characteristic shape, C.albicans dimorphism is an example of wall morphogenesis. Secondly, the wall is the contact point for attachment and subsequent invasion and contains specific adhesin molecules. Thirdly, the wall acts as a protective barrier and is an obstacle that must be considered in the construction and design of antifungal drugs that need to enter the cell for their effective action. In the wall are secreted hydrolytic enzymes and components that act as immunogenic determinants and immunomodulators. Finally, the $\beta$-glucans and chitin of the pathogen are not present in the host and hence these compounds and particularly the enzymes involved in their biosynthesis 
and degradation and potentially safe targets for antifungal agents. It is not surprising therefore that the architecture of the fungal cell wall and the mechanisms of wall synthesis and degradation are currently areas of intensive research effort. The cell wall comprises a mosaic of components and it is the discussion of these components that is the subject of this paper. The cell envelope and cell wall of Candida albicans has recently been reviewed by Shepherd et al. ${ }^{1)}$; Reiss ${ }^{2)}$; Shepherd ${ }^{3)}$; Odds $^{4)}$; Shepherd \& Gopal ${ }^{5)}$.

\section{Dynamic nature of the cell wall}

A major difficulty encountered in the investigation and description of the cell wall of Candida albicans is defining a typical wall. In addition to the qualitative and quantitative differences found between the yeast and mycelial cells 6,7$)$ we know that the wall of yeast cells alters during growth cycle and in different media ${ }^{8-10)}$. Tronchin et al. ${ }^{11)}$ have described the dynamic changes that occur on the cell surface during germ-tube formation including rapid synthesis and degradation of surface mannoproteins. In a study on coaggregation of Streptococci with C.albicans ${ }^{12)}$ it was found that starving the yeast cells for a period of only 30 minutes promoted the bacterial/fungal attachment. The induction of the adhesin was inhibited by protein synthesis inhibitors implying new protein synthesis was occuring at the surface. Collectively, these studies highlight the subtle and rapid changes that occur in the cell wall under different environmental and physiological conditions.

\section{Cell composition and ultrastructure}

The cell wall makes up approximately $30 \%$ of the total weight of the cell and a number of studies have shown that the wall is composed of mannoproteins, $(20-30 \%) ; \beta 1,3$ linked glucans $(25-35 \%) ; \beta 1,6$ linked glucans (35$45 \%)$ and small quantities of chitin (0.6-2.7 $\%)$, protein (5-15\%) and lipid (2-5\%) 13-16,7). The glucan and mannoprotein components of yeast and hyphal cells are similar although hyphal cells contain at least 3 times as much chitin as yeast cells $7,14,17)$. Transmission electron microscopy studies have shown the wall to be composed of a number of different layers and the thickness and number of these layers varies depending upon the morphology and the stage of growth ${ }^{18-22)}$. Although the striated appearance of the wall in cross section indicates layers of different chemical composition it is likely that the changes in electron density reflect quantitative rather than complete qualitative differences. Fig. 1 is a schematic diagram showing the architecture, composition and organisation of the C.albicans cell wall. The outermost layer is composed of mannoprotein although mannoprotein is also distributed throughout the entire wall. This has been shown with lectin binding studies and extraction of the cell wall with different solvents ${ }^{23}$, ${ }^{24)}$, cytochemical staining ${ }^{25)}$ and cross reaction of ferritin-conjugated antibodies ${ }^{26)}$. The remainder of the wall is made up of a network of the structural microfibrillar components $\beta$ glucans and chitin. These molecules form a scaffold which is enmeshed in a matrix of amorphous components including mannoproteins and proteins. Tronchin et al. 27) used wheat agglutinin to show that one layer of chitin was distributed in the inner wall layer near the plasma membrane but that there were smaller amounts found disbursed throughout the outer wall layers. In this organisation the fibrils would be resistant to stretching while the matrix would resist compression and act to trap soluble components such as wall enzymes. It should be noted however, that the interpretation of electronmicrographs must be made with caution as artifacts can arise from differential staining, staining of minor components, drying and fixation procedures.

\section{Outer surface of $C$. albicans}

A number of workers have demonstrated an outer cell wall coat variously called slime layer, mucous layer or fuzzy layer ${ }^{19,22,28,29)}$ and this layer is believed to play an important role in pathogenicity, phagocytosis and adherence. In addition the mannoproteins on the outer surface are the main immunogenic determinants in a Candida cell. It is known that this 


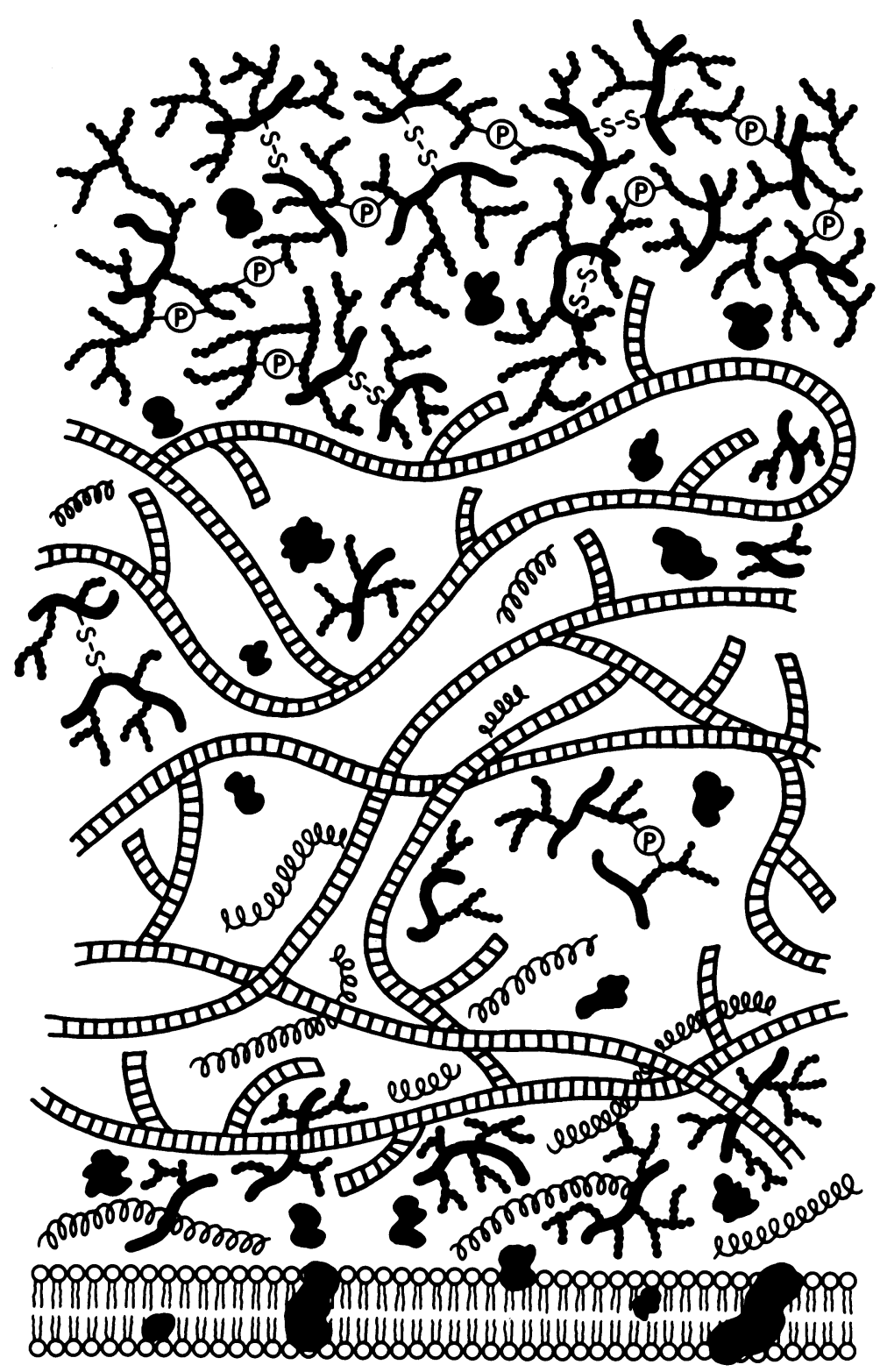

Fig. 1. Schematic diagram of the architecture of the C. albicans cell wall.

The molecules depicted are : chitin (momn); $\beta$ glucan microfibrils, mannoprotein, ( $\mathcal{S}$ ); extracellular enzymes, ( $\beta$ ); disulphide bridges, (-s-s-); phosphoester linkages, (-B) ).

outer layer undergoes considerable alteration depending on the mode of growth ${ }^{18,20,22)}$. Fig. 2 shows that in the developing germ-tube there are distinct fibrils arranged radially and perpendicular to the cell but these are absent from the mother cells. McCourtie \& Douglas ${ }^{8)}$ have demonstrated that the formation of this outer fibrillar/flocular layer is promoted by growing yeast cells of $C$. albicans in the presence of high concentrations of galactose and sucrose. The study of Howlett \& Squiers ${ }^{30}$ ) demonstrated the importance of the floccular 


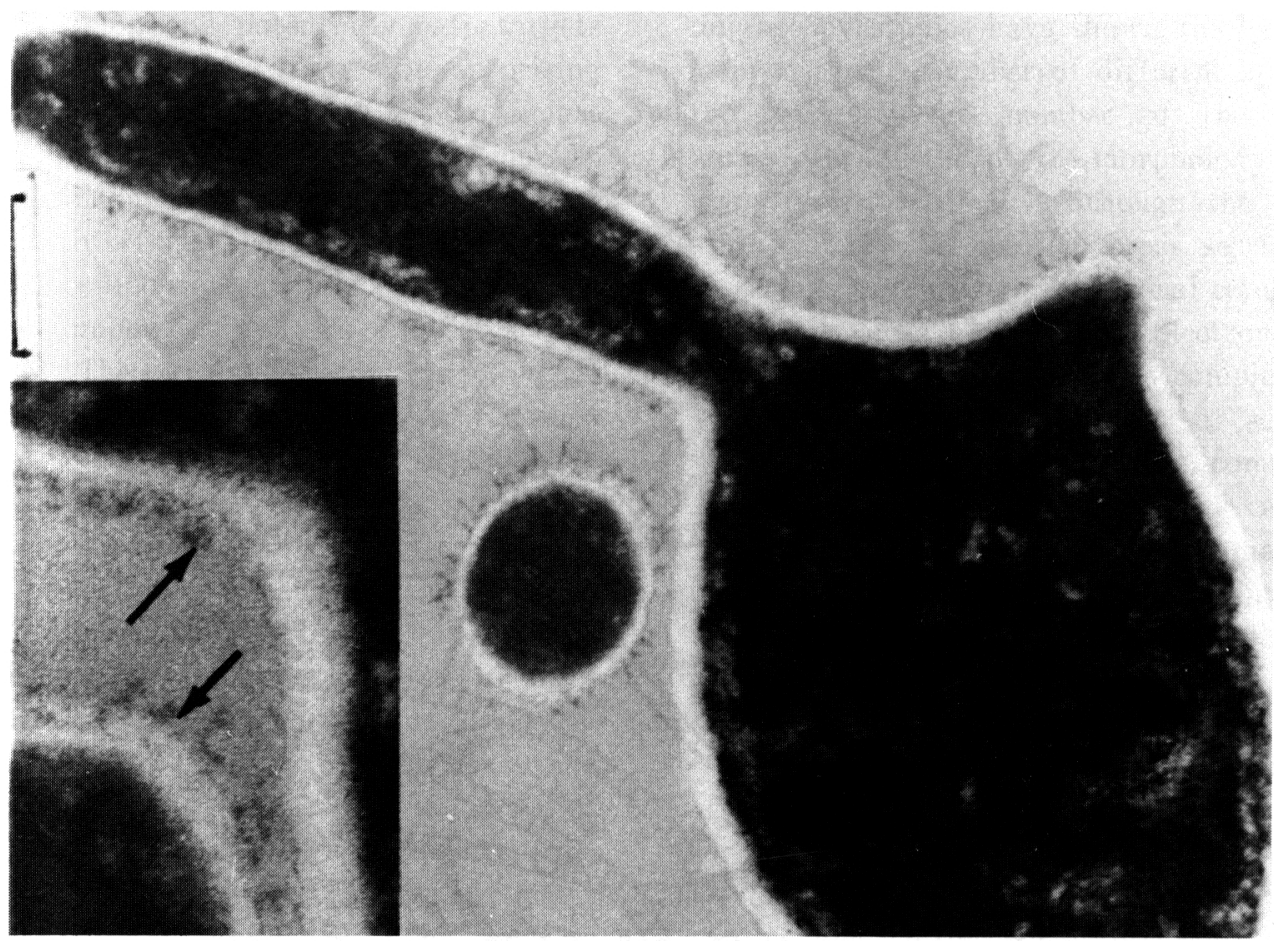

Fig. 2. Germ-tube fibrils. Ultra-thin section through a germ-tube-forming cell which was fixed in paraformaldehyde plus glutaraldehyde and postfixed with osmium. The cell wall is predominantely electron lucent with a thin electron-dense outer layer. An electron-dense outer layer of the germ-tube wall is shown (arrows in inset). In the cross-sectioned germ tube, the fibrils are seen to be arranged radially and perpendicular to the cell wall. Stained with lead citrate for $45 \mathrm{~min}$. Marker bar $=0.6 \mu \mathrm{m}$. (From Hubbard MJ, Sullivan PA and Shepherd MG, Can J Microbiol, 31:696, 1985. With permission).

layer in mediating adhesion of Candida to oral mucosal cells. Horisberger and Clerc ${ }^{31)}$ have described an apical concentration of anionic sites on germ-tubes and developing hyphae. The anionic sites are associated with the outer fuzzy coat and are believed to be derived from the phosphate groups on mannoproteins. These authors suggest that the anionic sites play an important role in tissue colonization.

Finally, the outer surface of the C.albicans wall contains receptors. The receptor for the C3 fragments of human complement C3d and iC3b has been characterized by several groups 32-34). In mammalian cells the $\mathrm{iC} 3 \mathrm{~b}$ interacts with the CR3 receptor on phagocytic cells promoting phagocytosis and stimulating the release of intracellular microbiocidal agents such as superoxide or myeloperoxidase. Therefore, the receptor may allow Candida cells to bind the $\mathrm{iC} 3 \mathrm{~b}$ non covalently and avert recognition by neutrophil CR3. In this way, the C.albicans surface receptor for the C 3 fragment promotes pathogenicity by inhibiting phagocytosis ${ }^{34)}$. Immunofluorescence studies have shown that plasma and matrix host proteins bind specifically to the surface of germtubes ${ }^{35}$ ) and this adherence is mediated by adhesins with molecular weights of 60,68 and $200 \mathrm{kDa}$. Tronchin et al11) have shown with Western blotting experiments that these adhesins interact with the host proteins laminin, fibrinogen and $\mathrm{C} 3 \mathrm{~d}$ and speculate that the same fungal components posses a variety of biological functions. Laminin has been impli- 
cated in both adhesion and pathogenesis of bacterial infections and therefore the germ tube specific surface receptors for laminin could mediate attachment of these cells to basement membranes and so contribute to the establishment of candidiasis.

\section{Cell wall polymers}

\section{Glucan}

Two lines of evidence indicate that the $\beta$ glucans impart the structural strength. Firstly, osmotically sensitive cells are generated after degradation of whole yeast cells with a purified $\beta 1,3$ glucanase ${ }^{36)}$. Secondly, protoplasts of $C$.albicans regenerated in simple medium of magnesium chloride and glucose give osmotically resistant cells that have not incorporated mannoprotein into the wall ${ }^{37)}$. Fig. 3 shows the fibrils of glucan forming a mesh around the protoplast cell. Although mannoprotein was not incorporated into the walls of these cells it was secreted into the medium. The classical protocol for obtaining fungal wall glucans (reviewed in 38) is fractionation on the basis of solubility in acid and alkali. Analysis of C. albicans glucans obtained in this manner by methylation, glc mass spectroscopy and ${ }^{13} \mathrm{C}$ NMR showed that $\beta 1,6$ glucan was the major polymer and that it was highly branched and soluble. There was also a branched $\beta 1,3$ glucan and mixed $\beta 1,3 / \beta 1,6$ glucan linked to chitin. The ratio of $\beta 1,3$ - to $\beta 1,6$ - glucan was similar in yeast and hyphal cells indicating that the morphology of C.albicans is not determined by the ratio of these linkages. However, the insoluble glucan from germ-tube forming cells contained considerably more $\beta 1,3$ linkages than that found in yeast and hyphal cells ${ }^{6}$. If the $\beta 1,3-\beta 1,6$ ratio in the mother cell is taken into account it would appear that during the early stages of germ-tube formation there is almost exclusive synthesis of $\beta 1,3$-linked glucans and this is analogous to the situation observed with regenerating

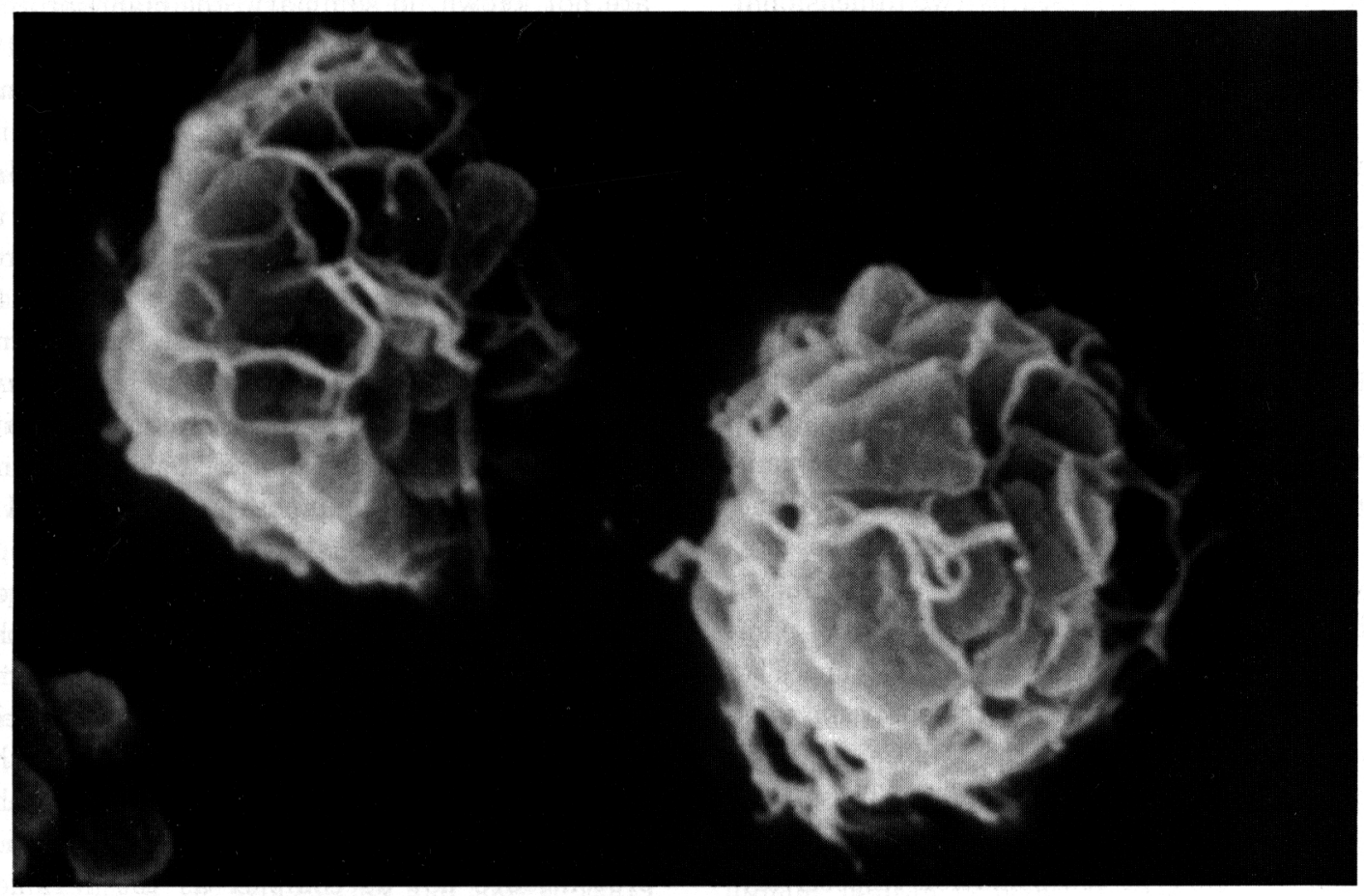

Fig. 3. Scanning electron microscopy of glucan nets forming on regenerating spheroplasts. The conditions for regeneration were $3 \mathrm{~h}$ at $30^{\circ} \mathrm{C}$ in a medium of $0.6 \mathrm{M} \mathrm{MgCl} 2$ and $50 \mathrm{mM}$ glucose. 
spheroplasts ${ }^{37,39)}$ which preferentially synthesize $\beta 1,3$ glucans. Surarit et al. ${ }^{40)}$ isolated the insoluble glucan chitin fraction from regenerating spheroplasts of C.albicans and mass spectrometry analysis confirmed a glycosidic linkage between the 6th position of G1cNAc on chitin and the 1 position of a $\beta 1,6$ glucan. Chitin is dispersed around the entire wall 27 ) and its association with glucan would provide a structural scaffold to which the remaining components attach. There are also reports of glucan mannoprotein complexes ${ }^{41)}$ but the nature of these linkages has not been established. A major difficulty in cell wall chemistry is obtaining molecules for analysis that are identical to those in the intact wall of the organism under study. Extremes of temperatures, and $\mathrm{pH}$ and extraction with solvents causes degradation and rearrangement. Gopal and Shepherd (unpublished results) have solubilized glucans from the wall by partial zymolyase degradation. The first glucan fraction to be solubilized was analysed by two dimensional ${ }^{1} \mathrm{H}$ and ${ }^{13} \mathrm{C} \mathrm{NMR}$ and the hetronuclear spectrum confirmed (i) a pure glucan of glucose and (ii) a $\beta$ linked polymer. While the first zymolyase treatment released a $\beta 1,3$ glucan, the second zymolyase treatment gave a mixture of $\beta 1,3-\beta 1,6$ glucan and mannoproteins. High resolution solid state ${ }^{13} \mathrm{C}$ NMR has been performed on the insoluble glucan (Gopal \& Shepherd, unpublished results) and the spectra analysed according to the assignments given by Saito ${ }^{42}$. Solid state ${ }^{13} \mathrm{C}$ NMR gives information on the structure of both non crystalline and crystalline insoluble polymers. The spectra showed ${ }^{1)}$ typical features of a $\beta 1,3$ glucan with the anomeric peak of $\mathrm{Cl}$ at $103.7 \mathrm{ppm}$ and the $\mathrm{C} 2$ and $\mathrm{C} 5$ peaks at $74.2 \mathrm{ppm}$. The most noteworthy feature of the spectrum was the doublet signal due to the C3; $\mathrm{Ca}$ at 85.7 ppm and $\mathrm{Cb}$ at $83.5 \mathrm{ppm}$ (Fig. 4). These two C3 signals correspond to the laminarin type and paramylon type conformation respectively 42). Finally, from the relative proportions of the two C3 signals we conclude that the degree of polymerisation is greater than 400 . From

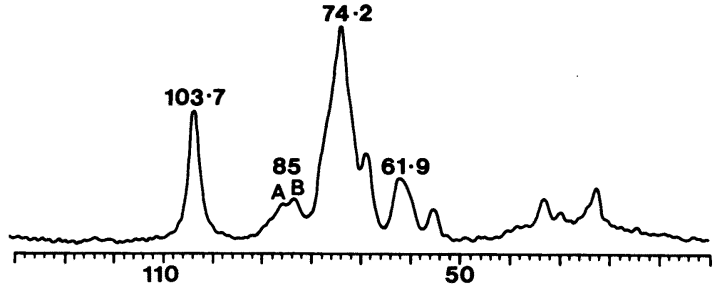

Fig. 4. The $75.43 \mathrm{MHz}{ }^{13} \mathrm{C}-\mathrm{CP}-\mathrm{MAS}$ NMR spectrum of C. albicans insoluble wall glucan. Contact time was $500 \mu$ sec.

these data and by analogy with other structural glucans such as cellulose and paramylon it is concluded that this molecule would indeed act as a major structural component of the wall. There is also evidence that these structural $\beta$ glucans form helical structures ${ }^{43)}$.

\section{Mannoproteins}

Despite the large number of studies completed on C.albicans mannoprotein ${ }^{44}$ and reviewed in 2) and 3) detailed structures for either the polysaccharide portion or the protein portion are not known. In summary, the mannoprotein fraction makes up approximately 20 to $30 \%$ of the cell wall, they are the major antigenic components of intact and mycelial cells, and as shown in Fig. 5, their structures are similar to that of the mannoproteins found in $S$. cerevisiae. The major portion of the mannoprotein is an $\alpha 1,6$-linked polymannose joined to the protein through a chitobiose bridge and asparagine. In the outer chain of C.albicans mannoproteins $60-70 \%$ of the mannose units are substituted at the 2 and 3 position and oligosaccharides of mannose are joined by 1,2 linkages and occasionally 1,3 linkages. It is the heterogeneity in these outer regions which give rise to antigenic determinants and the two serotypes of C. albicans. Elorza et al ${ }^{45)}$ have estimated that $12 \%$ of the mannoprotein of the wall is O-linked. The molecular weight of the isolated mannoprotein depends on the method of preparation. The O-linked mannoproteins are not as complex as the N-linked molecules. Gopal \& Shepherd (unpublished) carried out controlled $\beta$ elimination on a highly purified cell wall mannoprotein fraction 


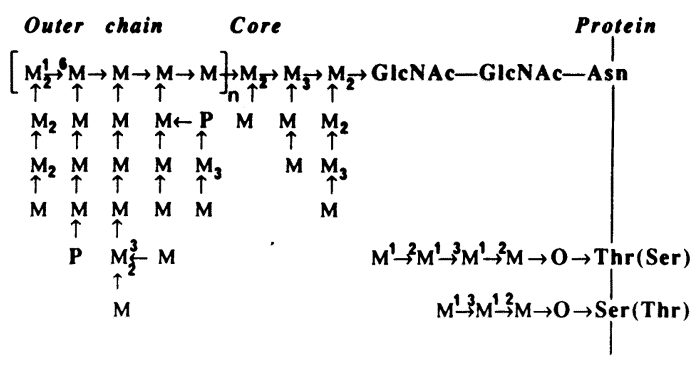

Fig. 5. Proposed structure for Candida albicans mannoprotein.

and fractionated the products on a Biogel P2 sizing column. A mannobiose, mannotriose and mannotetraose was isolated from the column. The proton NMR of the oligosaccharides gave the linkage analysis shown in Fig. 5. These linkages are different from that found in S.cerevisiae and may be important in the taxonomy of the Candida species. In the C. albicans wall mannoproteins the phosphate content is between 0.2 and $1 \%$ whereas in $S$. cerevisiae mannoproteins the phosphate content is less than $0.1 \%$. The presence of this highly charged phosphate group on the outer regions of the wall would affect the way these cells are attracted to and indeed attached to other surfaces. The anionic sites on developing germtubes ${ }^{31)}$ are believed to be from the negatively charged phosphate groups on the mannoproteins. Details on the mannophosphate linkage are not available as most of the published studies on the structures of C.albicans mannoproteins used isolation procedures that would have destroyed phosphoester linkages. Early studies used Fehling solution where acid was employed to dissociate the copper mannan complex. This procedure would destroy $\alpha 1,3$ mannobiosyl and phosphodiester linkages. The Cetavalon-borate mannoprotein complexes are larger but again separation of the complex must be done in the absence of strong acid. Molloy et al. 46) carried out vectorial iodination on proteins of the cell surface and showed that a zymolyase degradation of a wall preparation released material that was not contaminated with membrane and cytosolic proteins but did release $93 \%$ of the iodine with a specific activity 45 fold higher than the original SDS extract. The requirement for $\beta 1,3$ glucanase to release the 125I labelled material is consistent with either covalent attachment or tight entrapment of the labelled proteins in the cell wall glucans. The major iodinated material moved as a diffuse band at $260 \mathrm{kDa}$ but it is not clear whether this is one mannoprotein or a mixture. By analogy with the study of Frevert and Ballou ${ }^{47)}$ on S. cerevisiae this 260 $\mathrm{kDa}$ mannoprotein may well be the major structural glycoprotein in the cell wall. The $260 \mathrm{kDa}$ fraction was composed of $1.5 \%$ protein and $98.4 \%$ hexose and analysis of the peptide portion showed it contained 36-38\% serine and threonine residues typical of mannoproteins enriched in O-linked oligosaccharides. Elorza et al ${ }^{45)}$ found C.albicans mannoproteins to contain $7 \%$ protein and $92 \%$ carbohydrate, predominantly mannose with a small amount of glucose. Saxena et al. ${ }^{48)}$ annalysed mannans from two relatively avirulent mutant strains of C.albicans and found that the mannan on the avirulent strains was more susceptible to acid hydrolysis indicating differences in phosphoester linkages. Cell surface mutants of C.albicans have also been analysed by Whelan et al49) and these mutants exhibited a range of different phenotypes and chemotypes. The changes in the mannoprotein structure of the mutants implied that the immunodominant determinant of C.albicans are not directly involved in colonization ability. Again there was loss of a signal characteristic of the mannosyl $\alpha$-phosphate linkage. The mannoproteins of $C$. albicans defines two serotypes; serotype $A$ and serotype $B^{50,51)}$ and these two serotypes are distinguished by the side chain oligosaccharides attached to the backbone 1, 6 mannose. The mannoprotein immunochemistry and immunology has been reviewed by Reiss ${ }^{2}$. Briefly in serotype A mannan the immunodominant haptan is believed to be a linear $\alpha-1$, 2 linked mannohexaose with an $\alpha-1,3$ linkage at the penultimate sugar from the reducing end. The B serotype appears to contain a bran- 
ched molecule. It should be noted, however, that the structures postulated do not take into account the important role of phosphate residues and antigenic responses ${ }^{52)}$ and there is still some debate on the role of $\beta$-linked mannose residues the presence of which are indicated from proton NMR spectra.

\section{Proteins}

The number and quantity of proteins in the cell wall remains a matter of considerable debate. Some reports show as many as 40 discrete bands on electrophoresis. However, the study of Molloy et al46) highlights the contamination that occurs in walls obtained by traditional extraction methods. In that study ${ }^{46)}$ there were only 12 wall proteins that could be resolved by electrophoresis and autoradiography that are accessible to vectorial iodination. The threadlike fibrils extending from C. albicans to epithelial cells are believed to be proteins. In addition the self aggregating clumps of germ-tubes can be dispersed by digestion with trypsin or sulphydryl reagents but not with $\alpha$-mannosidase ${ }^{53)}$. Finally, it is known that the wall contains a number of enzymes including $\mathrm{N}$-acetylglucosaminidase, acid phosphatase, proteinase, glucanase and chitinase (reviewed in 4). There is evidence that the proteinase acts as an aggressin and is a determinant in the pathogenicity of C.albicans $^{54)}$.

Cell wall biosynthesis and model of wall formation

The essential elements of wall biosynthesis are shown in Fig. 6. It is proposed that vesicles originate in the endoplasmic reticulum in a membraneous body equivalent to the Golgi apparatus. These vesicles contain new material for the plasma membrane as well as membrane bound enzymes, soluble enzymes, highly processed mannoproteins and perhaps a number of wall polymer primers. These vesicles proceed to the point of growth in the cell along actin fibrils and at the plasma membrane there is accretion of this new membrane from the vesicle into the plasma membrane. Yokoyama et $\left.a l^{55}\right)$ have demonstrated that actin microfilaments are important in apical cell elongation of C.albicans hyphae whereas the cytoplasmic microtubules are not essential. The plasma

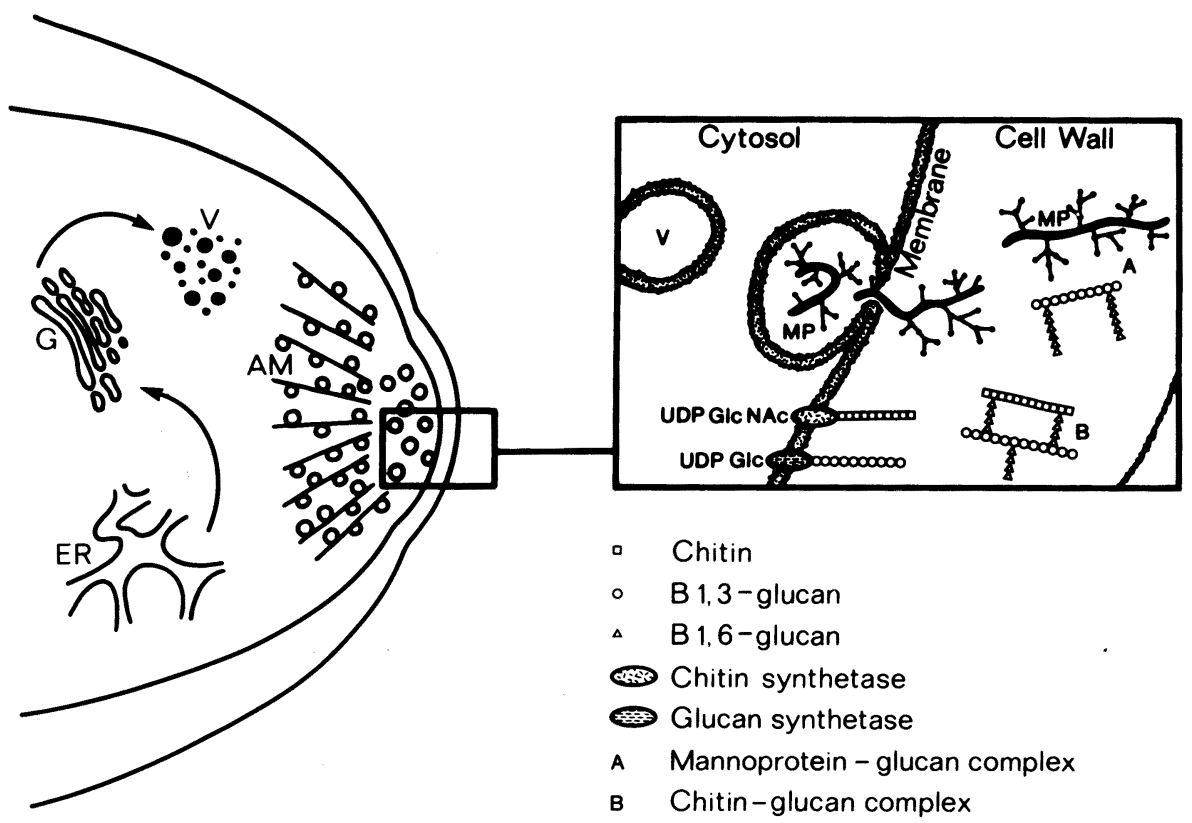

Fig. 6. Cellular and biochemical mechanisms included in C. albicans wall formation. 
membrane can be recycled through the process of endocytosis. After fusion of the vesicle with the plasma membrane the mannoproteins are released into the cell wall (Fig. 6, inset).

Chitin and glucan are synthesized by transmembrane enzymes catalysing the vectorial synthesis of these polymers with the precursors UDP $\mathrm{N}$-acetylglucosamine and UDP glucose inside the cell and the product extruded through into the wall. We do not understand the fine controls of these enzymes nor the mechanisms that activate them at the points of growth. When the products emerge from the cell membrane they undergo intussusception into the expanding wall. At this point the molecules are linear and many questions remain unanswered as to how the glucans are 1) branched 2) cross-linked with other polymers such as chitin and 3) complexed with mannoproteins. One proposal is that $\beta$-glucanases in the cell wall clip the existing glucan and allow additional glucan molecules to be incorporated. This is summarized in Fig. 7 which shows secondary wall formation. The secondary wall cross-linkages reinforce the wall structure and provide a network which could retain both the water soluble mannoprotein and the cell wall enzymes.The studies of Sonnenberg \& Wessels ${ }^{56)}$ with Schizophyllum commune showed that at the growing apex glucan and chitin are synthesized as unbranched polymers but in the subapical region modifications occur, particularly cross-linking.

\section{References}

1) Shepherd MG, Poulter RTM and Sullivan PA : Candida albicans: Biology, genetics, and pathogenicity. Ann Rev Microbiol 39 : 579-614, 1985.

2) Reiss E : Molecular Immunology of Mycotic and Actinomycotic Infections. Elsevier, New York, 1986.

3) Shepherd MG : Cell Envelope of Candida albicans. Crit Rev Microbiol 15 : 7-25, 1987.

4) Odds FC : Morphogenesis in Candida, with special reference to C. albicans. In Candida and Candidosis. A Review and Bibliography. 2nd Edition, p.42-59, Bailliere
Tindall, London, 1988.

5) Shepherd MG and Gopal PK : Candida albicans: Cell Wall Physiology and Metabolism. FEMS Symposium Candida and candidamycosis. (Tumbay E ed) (in press), 1990.

6) Gopal PK, Shepherd MG and Sullivan $P$ A : Analysis of wall glucans from yeast, hyphal and germ-tube forming cells of Candida albicans. J Gen Microbiol 130 : 3295-3301, 1984.

7) Sullivan PA, Chiew YY, Molloy C, Templeton MD and Shepherd MG : An analysis of the metabolism and cell wall composition of Candida albicans during germ-tube formation. Can J Microbiol 29 : 1514-1525, 1983.

8) McCourtie J and Douglas LJ : Relationship between cell surface composition of Candida albicans and adherence to acrylic after growth on different carbon sources. Infect Immun 32:1234-1241, 1981.

9) Kennedy MJ and Sandin RL : Influence of growth conditions on Candida albicans adhesion, hydrophobicity and cell wall ultrastructure. J Med Vet Mycol $26: 79-$ 92, 1988.

10) Hazen BW and Hazen KC : Dynamic expression of cell surface hydrophobicity during initial yeast cell growth and before germtube formation of $C$. albicans. Infect Immun 56 : 2521-2528, 1988.

11) Tronchin G, Bouchara JP and Robert R : Dynamic changes of the cell wall surface of Candida albicans associated with germination and adherence. Eur $\mathrm{J}$ Cell Biol 50 : 285-290, 1989.

12) Jenkinson HF, Lala HC and Shepherd M G: Coaggregation of Streptococcus sanguis and other streptococci with Candida albicans. Infect Immun 58 : 1429-1436, 1990.

13) Bishop CT, Blank $F$ and Gardner PE: The cell wall polysaccharides of Candida albicans: glucan, mannan and chitin. Can J Chem $38: 869-881,1960$.

14) Chattaway FW, Holmes MR and Barlow AJE : Cell wall composition of the mycelial and blastospore forms of Candida albicans. J Gen Microbiol 51 : 367-376, 1968.

15) Hasenclever HF and Mitchell WO : A study of yeast surface antigens by agglutination 
inhibition. Sabouraudia $3: 288-300,1964$.

16) Yu RJ, Bishop CT, Cooper FP, Hasenclever $\mathrm{HF}$ and Blank $\mathrm{F}$ : Structural studies of mannans from Candida albicans (serotype A and B) Candida parapsilosis, Candida stellatoidea and Candida tropicalis. Can J Chem 45 : 2205-2211, 1967.

17) Braun PC and Calderone RA : Chitin synthesis in Candida albicans: comparison of yeast and hyphal forms. J Bacteriol 133 : 1472-1477, 1978.

18) Cassone A, Simonetti N and Stippoli V : Ultrastructural changes in the wall during germ-tube formation from blastospores of Candida albicans. J Gen Microbiol 77 : 417 -426, 1973.

19) Djaczenko $W$ and Cassone A : Visualization of new ultrastructural components in the cell wall of Candida albicans with fixatives containing TAPO. J Cell Biol 52 : 186-190, 1971.

20) Scherwitz $C$, Martin $R$ and Ueberberg $H$ : Ultrastructural investigations of the formation of Candida albicans germ tubes and septa. Sabouraudia 16 : 115-124, 1978.

21) Poulain D, Tronchin G, Dubremetz JF and Biguet $J$ : Ultrastructure of the cell wall of Candida albicans blastospores: study of its constitutive layers by the use of a cytochemical technique revealing polysaccharides. Ann Microbiol 129A : 141153, 1978.

22) Hubbard MJ, Sullivan PA and Shepherd MG : Morphological studies of $\mathrm{N}$-acetylglucosamine induced germ tube formation by Candida albicans. Can J Microbiol 31 : 696-701, 1985.

23) Cassone A, Mattia E and Boldrini L : Agglutination of blastospores of Candida albicans by concanavalin A and its relationship with the distribution of mannan polymers and the ultrastructure of the cell wall. J Gen Microbiol 105 : 263-273, 1978.

24) Tronchin G, Poulain D and Biguet $\mathrm{J}$ : Cytochemical and ultrastructural studies of the cell wall of Candida albicans. I . Localization of mannan by means of concanavalin A on ultrathin sections. Arch Microbiol 123 : 245-249, 1979.

25) Cassone A, Kerridge D and Gale EF : Ultrastructural changes in the cell wall of
Candida albicans following cessation of growth and their possible relationship to the development of polyene resistance. $\mathrm{J}$ Gen Microbiol 110 : 339-349, 1979.

26) Venezia RA and Lachapelle RC: The use of ferritin-conjugated antibodies in the study of cell wall components of Candida albicans. Can J Microbiol 19 : 1445-1448, 1973.

27) Tronchin G, Poulain D, Herbaut $J$ and Biguet $\mathrm{J}$ : Localization of chitin in the cell wall of Candida albicans by means of wheat germ agglutinin. Eur $J$ Cell Biol $26: 121-128,1981$.

28) Pesti M, Novak EK, Ferenczy L and Svoboda A : Freeze fracture electron microscopical investigation of Candida albicans cells sensitive and resitant to nystatin. Sabouraudia 19 : 17-26, 1981.

29) Tronchin G, Poulain D, Herbaut $J$ and Biguet $\mathrm{J}$ : Cytochemical and ultrastructural studies of Candida albicans. II. Evidence for a cell wall coat using Concanavalin A. J Ultrastruct Res 75 : 50-59, 1981.

30) Howlett JA and Squier CA : Candida albicans ultrastructure: Colonization and invasion of oral epithelium. Infect Immun 29 : 252-260, 1980.

31) Horisberger $M$ and Clerc MF : Ultrastructural localization of anionic sites on the surface of yeasts, hyphal and germ-tube forming cells of Candida albicans. Eur J Cell Biol 46 : 444-452, 1988.

32) Heidenreich F and Dierich MP : Candida albicans and Candida stellatoidea, in contrast to other Candida species, bind $\mathrm{iC} 3 \mathrm{~b}$ and $\mathrm{C} 3 \mathrm{~d}$ but not C3b. Infect Immun 50 : 598-600, 1985.

33) Calderone RA, Lineman L, Wadsworth E and Sandberg AL: Identification of C $3 \mathrm{~d}$ receptors on Candida albicans. Infect Immun 56 : 252-258, 1988.

34) Gilmore BJ, Retsinas EM, Lorenz JS and Hostetter MK : An iC3b receptor on Candida albicans: structure, function, and correlates for pathogenicity. J Infect Dis $157: 38-46,1988$.

35) Bouali A, Robert R, Tronchin G and Senet $\mathrm{JM}$ : Characterization of binding of human fibrinogen to the surface of germ-tubes and mycelium of Candida albicans. J Gen 
Microbiol 133 : 545-551, 1987.

36) Gopal P, Sullivan PA and Shepherd MG : Metabolism of $\left[{ }^{14} \mathrm{C}\right]$ glucose by regenerating spheroplasts of Candida albicans. J Gen Microbiol 130 : 325-335, 1984.

37) Gopal PK, Sullivan PA and Shepherd M $G$ : Isolation and structure of glucan from regenerating spheroplasts of Candida albicans. J Gen Microbiol 130 : 1217-1225, 1984.

38) Fleet $\mathrm{GH}:$ Composition and structure of yeast cell walls. In Current Topics in Medical Mycology (McGinnis MR ed), vol.1, p24, Springer-Verlag, New York, 1985.

39) Kreger DR and Kopecka M : On the nature and formation of the fibrillar nets produced by protoplasts of Saccharomyces cerevisiae in liquid media: an electronmicroscopic, X-ray diffraction and chemical study. J Gen Microbiol 92 : 207-220, 1975.

40) Surarit R, Gopal PK and Shepherd MG : Evidence for a glycosidic linkage between chitin and glucan in the cell wall of Candida albicans. J Gen Microbiol 134 : 17231730, 1988.

41) Friis $J$ and Ottolenghi $P$ : The genetically determined binding of Alcian blue by a minor fraction of yeast cell walls. Comp Rend Trav Lab Carlsberg 37 : 327-341, 1970.

42) Saito H, Tabeta R, Sasaki $T$ and Yoshioka $\mathrm{Y}: \mathrm{A}$ high-resolution solid-state ${ }^{13} \mathrm{C}$ NMR study of (1-3)- $\beta$-D-glucans from various sources. Conformational characterisation as viewed from the conformation-dependent ${ }^{13} \mathrm{C}$ chemical shifts and its consequence to gelation property. Bull Chem Soc Jpn 59 : 2093-2101, 1986.

43) Marchessault RH and Deslandes Y : Texture and crystal structure of fungal polysaccharides. In Fungal Polysaccharides (Sanford PS, Matsuda K eds) American Chemical Society Symposium series no. 126. pp.221-250, Washington, DC: American Chemical Society.

44) Kogan G, Pavliak V and Masler L : Structural studies of mannans from the cell walls of the pathogenic yeasts Candida albicans serotypes $\mathrm{A}$ and $\mathrm{B}$ and Candida parapsilosis. Carbohydr Res 172 : 243-253, 1988.

45) Elorza MV, Marcilla A and Sentandreu $\mathrm{R}$ : Wall Mannoproteins of the yeast and mycelial cells of Candida albicans: Nature of the glycosidic bonds and polydispersity of their mannan moieties. J Gen Microbiol 134 : 2393-2403, 1988.

46) Molloy CE, Shepherd MG and Sullivan P A : Identification of envelope proteins of Candida albicans by vectorial iodination. Microbios 57 : 73-83, 1989.

47) Frevert $J$ and Ballou CE : Saccharomyces cerevisiae structural cell wall mannoprotein. Biochemistry $24: 753-759,1985$.

48) Saxena A, Hammer CF and Cihlar RL: Analysis of mannans of two relatively avirulent mutant strains of Candida albicans. Infect Immun $57: 413-419,1989$.

49) Whelan WL, Delga JM, Wadsworth E, Walsh TJ, Kwon-Chung KJ, Calderone R and Lipke PN : Isolation and characterization of cell surface mutants of Candida albicans. Infect Immun 58 : 1552-1557, 1990.

50) Summers DF, Grollman AP and Hasenclever HF : Polysaccharide antigens of the Candida cell wall. J Immunol 92 : 491-499, 1964.

51) Hasenclever $\mathrm{HF}$ and Mitchell WO : Antigenic studies of Candida. I. Observation of two antigenic groups in Candida albicans. J Bacteriol 82 : 570-573, 1961.

52) Okubo Y, Honma Y and Suzuki S : Relationship between phosphate content and serological activities of the mannans of Candida albicans strains NIH A-207, NIH B-792, and J-1012. J Bacteriol $137: 677-680$, 1979.

53) Rahary L, Bonaly R, Lematre $J$ and Poulain D: Aggregation and disaggregation of Candida albicans germ-tubes. FEMS Microbiol Lett 30 : 383-387, 1985.

54) Staib F : Proteolysis and pathogenicity of Candida albicans strains. Mycopathol Mycol Appl 37 : 345-348, 1969.

55) Yokoyama K, Kaji H, Nishimura $K$ and Miyaji $M$ : The role of microfilaments and mictrotubules in apical growth and and dimorphishm of Candida albicans. J Gen Microbiol 136 : 1067-1075, 1990.

56) Sonnenberg ASM, Sietsma JH and Wessels JGH : Spatial and temporal differences in the synthesis of (1-3) - $\beta$ - and (1-6) - $\beta$ linkages in a wall glucan of Schizophyllum commune. Exp Mycol 9 : 141-148, 1985. 